\title{
Remarks on the Translation of Noun Phrase Ellipsis from English into Arabic
}

\author{
Ali Algryani \\ Department of English Language and Literature, \\ Dhofar University, Oman
}

\begin{abstract}
This paper discusses the translation of noun phrase ellipsis (NP ellipsis) from English into Arabic. It aims to determine how NP ellipsis is rendered into Arabic and what implications its translation has on the target text. To achieve this, the study relies upon the analysis of authentic English texts and their Arabic translations. The analysis of the Arabic translations reveals that NP ellipsis is rendered by ellipsis or lexical repetition. Furthermore, there seems to be a tendency towards using lexical repetition in the translation of ellipsis, which raises the degree of explicitness in the translated text. The use of lexical repetition can be attributed to structural incompatibilities and differences in stylistic preferences between the two languages. Finally, the study shows that NP ellipsis is not always translated accurately, resulting in ambiguity and loss of the source text informative content. Therefore, further studies on the translation of other forms of ellipsis can show the potential renderings of ellipsis and their impacts on the target text.
\end{abstract}

Key words: cohesion, ellipsis, explicitness, explicitation, lexical repetition

Cites as: Algryani, A. (2020). Remarks on the Translation of Noun Phrase Ellipsis from English into Arabic. Arab World English Journal for Translation \& Literary Studies4 (1)124-36.

DOI: http://dx.doi.org/10.24093/awejtls/vol4no1.3 